\title{
Comportamento dos Equinos do Centro de Equoterapia do Instituto Federal Goiano - Campus Ceres
}

\author{
Warren Raphael Santos de Castro ${ }^{1}$, Heloisa Baleroni Rodrigues de Godoy ${ }^{*}$, Mônica Maria de \\ Almeida ${ }^{2} \&$ Marcelo Marcondes de Godoy ${ }^{2}$ \\ ${ }^{1}$ Departamento de Biologia, Instituto Federal de Educação, Ciência e Tecnologia Goiano - Campus Ceres. \\ ${ }^{2}$ Departamento de Zootecnia, Instituto Federal de Educação, Ciência e Tecnologia Goiano - Campus Ceres. \\ *E-mail para correspondência: heloisa.godoy@ifgoiano.edu.br
}

\begin{abstract}
RESUMO
Buscando avaliar o comportamento e as condições de bem-estar dos cavalos utilizados no Centro de Equoterapia do IF Goiano Ceres, GO, foram realizadas avaliações entre março e agosto de 2018, quanto ao temperamento, estado de saúde e comportamentos normais e estereotipados expressos antes, durante e após as sessões equoterápicas, turnos das sessões e diferenças individuais de cada animal. Não houve diferença para o temperamento quanto tempo de serviço semanal, idade do animal e condição física $(p>0,05)$. Os animais avaliados demonstraram temperamento adequados a cavalos utilizados para a finalidade equoterápica. As frequências cardíacas foram maiores antes das sessões, as frequências respiratórias foram maiores antes e até 15 minutos após o início das sessões $(p<0,05)$. Estação distraído foi o comportamento mais observado $(63 \%)$ que ocorreu com animais antes e após as sessões e a estação alerta (36\%) foi expressa com maior frequência durante as sessões $(p<0,05)$. Os comportamentos estereotipados foram pouco frequentes, sendo expressado em apenas um animal antes das sessões equoterápicas. Os indicadores de saúde, de condição corporal e parâmetros comportamentais avaliados estavam de acordo com os comportamentos da espécie, mostrando que os animais do Centro de Equoterapia do IF Goiano Ceres apresentam um bem-estar adequado.
\end{abstract}

Palavras-chave: Cavalos, Comportamentos estereotipados, Temperamento.

\section{ABSTRACT}

Equine Behavior of Equotherapy Center of Instituto Federal Goiano - Campus Ceres. The objective of this study was to evaluate the behavior and welfare of horses used in Equotherapy Center of the IF Goiano Campus Ceres. Evaluations were made between March and August of 2018 regarding temperament, health status and normal and stereotyped behaviors expressed before, during and after the equotherapeutic sessions, sessions (morning and afternoon) and individual differences of each animal. There was no difference for temperament, weekly service time, animal age and physical condition $(p>0.05)$. The evaluated animals showed adequate temperament to horses used for the equotherapeutic purpose. Cardiac and respiratory rates were higher before the sessions. However, respiratory rates remained high up to 15 minutes after the sessions $(p<0.05)$. The distracted behavior was more observed $(63 \%)$ in the animals before and after the sessions. Already the alert behavior $(36 \%)$ occurred more frequently during the sessions $(p<0.05)$. Health indicators, body condition and evaluated behavioral parameters were in agreement with those expected for the species showing that the animals of the Equotherapy Center of the IF Goiano Campus Ceres have an adequate welfare.

Keywords: Horses, Stereotyped behaviors, Temperament. 


\section{INTRODUÇÃO}

Ao longo do tempo, os homens e os cavalos (Equus caballus Linnaeus, 1758) vêm se relacionando de diversas formas. A domesticação do cavalo remonta a 3.500 anos a.C na região do atual Cazaquistão (Outram et al., 2009) e, desde então, o cavalo é utilizado para montaria, tração, meio de transporte e, mais recentemente, no auxílio ao tratamento de pessoas com deficiências físicas e/ou mentais ou pacientes com traumas mecânicos, tendo sido regulamentada em 2008 como recurso terapêutico pelo Conselho Federal de Fisioterapia e Terapia Ocupacional (Severo, 2010).

Na Equoterapia, devemos levar em consideração as qualidades dos movimentos do cavalo para o trabalho proposto a ele. Os fundamentos para os níveis de adestramento e para a teoria do treinamento básico devem atender à seguinte afirmação: um cavalo deve andar para a frente, forte, relaxado, com andaduras suaves, puras e que sejam capazes de promover o prazer e o conforto ao cavaleiro (Severo, 2010).

Ainda segundo Severo (2010), a Equoterapia se caracteriza pelo fato de o cavalo ser um importante motivador terapêutico. O fundamento principal é que a conformação do corpo do cavalo, ao se deslocar, provoca ondulações horizontais, verticais, longitudinais e rotacionais em sua coluna vertebral. Essas ondulações são transmitidas ao cavaleiro, que as absorve pelo funcionamento dos seus sistemas musculoesquelético e nervoso. O efeito dessas ações sobre a pelve e a coluna do cavaleiro, que se desloca montado, com o cavalo ao passo, permite que praticante realize, de forma reacional, os mesmos movimentos que faria como se deslocasse a pé e por seus próprios meios. Isso provoca no cavaleiro reações constantes de endireitamento e reajustes posturais, a cada deslocamento de seu centro de gravidade corporal.

Segundo a Associação Nacional de Equoterapia (ANDE - Brasil, 1999):

“A Equoterapia é um método terapêutico que utiliza o cavalo dentro de uma abordagem interdisciplinar nas áreas de saúde, educação e equitação, buscando o desenvolvimento biopsicossocial de pessoas com deficiência e/ou com necessidades especiais... emprega o cavalo como agente promotor de ganhos a nível físico e psíquico"

Para que seja garantido o sucesso do tratamento equoterápico, a escolha correta do animal é imprescindível. Desta forma, segundo Arantes et al. (2006) é desejável que o animal possua características que permitam o seu adequado contato com o paciente. As características desejáveis são docilidade, obediência, relação de confiança com praticante, resistência, rusticidade, facilidade de adaptação ao ambiente, grande peso corporal, para poder atender pacientes obesos, que aceite bem o contato, o toque, e que tenha comportamento de disponibilidade de ajudar (Arantes et al., 2006). 
Percebe-se, portanto, que o temperamento dos animais usados nas sessões, assim como os comportamentos que demonstram durantes as sessões é de extrema importância. Mas sabe-se também que os comportamentos demonstrados pelos animais se modificam quando fatores externos e internos estão em constante mudança ou em dissonância com a normalidade, levando o animal a apresentar comportamentos que não seriam considerados típicos da espécie (Severo, 2010).

A importância da avaliação dos comportamentos normais e anormais (estereotipados) dos indivíduos é evidenciada tanto em estudos nacionais quanto internacionais. No Brasil, várias pesquisas foram realizadas por Crizanto (2002), Rezende et al. (2006), Vieira (2006), Leal (2007), Pagliosa et al. (2008) e Gontijo et al. (2014) evidenciando os principais comportamentos em equinos submetidos à estabulação. McDonnell \& Haviland (1995) descreveram diversos comportamentos através da formulação de um etograma para a espécie equina.

De acordo com Konieczniak et al. (2014), os cavalos em liberdade passam em torno de 16 horas pastando, cerca de quatro horas interagindo com coespecíficos e o restante do tempo em repouso. Desta forma, animais sem atividades e distrações podem desenvolver comportamentos atípicos conhecidos como estereotipia. Para alguns autores, a estereotipia é parte do processo adaptativo dos animais em resposta ao estresse, já que, mesmo apresentando os comportamentos atípicos, os animais não apresentaram mudanças nas concentrações de cortisol, o que seria um indicativo de estresse, significando que o animal está adaptado às situações em que está exposto (Gontijo et al., 2014).

Conhecer algumas questões comportamentais é indispensável para garantir uma saudável relação entre os animais (Viana et al., 2011) e questões relativas ao bem-estar animal (BEA) estão cada dia mais presentes dentre os assuntos de interesse da comunidade civil, dos governos, órgãos nacionais e internacionais e de instituições acadêmicas em todo o mundo. Há grupos e instituições que atuam na ciência do BEA, ou seja, no estudo das reações psicofisiológicas dos animais frente a estímulos externos gerados pelo homem, com o objetivo de detectar possíveis situações de comprometimento da qualidade de vida, propondo medidas para minimizá-las ou aboli-las (Malinowski, 2004).

Quaisquer práticas que causem reações de incomodo (prolongado ou permanente) no animal, dor e exaustão são consideradas maus tratos (MAPA, 2015). A avaliação científica do bem-estar tornouse importante para constatar animais não ambientados às condições de criação que lhes são impostas, colocando-os em maior risco de enfermidades, circunstância que afeta o potencial produtivo (Gontijo et al., 2014).

A avaliação da qualidade do BEA envolve uma gama de indicadores que devem ser apreciados em conjunto. Para tal, foram criadas pela Farm Animal Welfare Council (FAWC), em 1993, as cinco liberdades, parâmetros que possibilitam quantificar a qualidade do bem-estar de um animal (FAWC, 1992), 
considerando que estes devem estar livres de fome e sede, com acesso a água limpa e alimento de boa qualidade para a manutenção de sua condição física; livres do desconforto para permitir um ambiente apropriado e confortável; livres de dor, injúria e doença; livres para expressar seu comportamento natural e livres de medo e distresse.

Porém, é conhecido que o simples fato do animal estar em cativeiro pode alterar o seu estado natural, mas não necessariamente é indicativo de que o seu bem-estar não esteja assegurado. Desta forma, o conceito das cinco liberdades foi repensado a partir de protocolos que buscassem desenvolver estratégias para medir o bem-estar dos animais em cativeiro em um projeto denominado Welfare Quality ${ }^{\circledR}$, que é baseado em quatro princípios básicos: boa alimentação, bom alojamento, boa saúde e comportamento adequado (Botreau et al., 2007; Welfare Quality ${ }^{\circledR}, 2011$; AWIN, 2015).

O Centro de Equoterapia do campus Ceres do Instituto Federal Goiano (IF Goiano) oferece, desde 2005, atendimento a crianças e adultos com necessidades físicas e/ou psicológicas tendo como ferramenta, o cavalo. Desta forma, o presente trabalho propõe-se a avaliar o bem-estar dos animais utilizados nas sessões de equoterapia do referido centro a partir de indicadores comportamentais, físicos e fisiológicos.

\section{MATERIAL E MÉTODOS}

A pesquisa foi desenvolvida no Centro de Equoterapia do Campus Ceres do Instituto Federal Goiano, com os cavalos que estiveram em serviço durante os meses de março a agosto de 2018 . Todos os procedimentos experimentais foram realizados de acordo com as normas éticas e aprovação do Comitê de Ética no Uso de Animais (CEUA) do IF Goiano, protocolo no 5362250517.

Nas instalações do Centro estavam alojados 16 cavalos, porém apenas sete estavam em serviço já que os demais se encontravam aposentados ou em treinamento. A tropa era composta na sua maior parte por mestiços, possuindo também alguns meio-sangue da raça Quarto de Milha e também da raça Piquira, sendo a maioria vindos de doação.

Os animais permaneciam estabulados apenas durante o dia, em baias individuais sem forração, concretadas, de tamanho $3 \times 2,5 \mathrm{~m}$, sendo liberados para pastejo em todos os demais períodos (final de tarde/noite e final de semana a partir do período vespertino da sexta-feira). Durante o pastejo, os animais ficavam soltos em grupo, tendo disponibilidade de três piquetes de aproximadamente 0,5 ha cada, que são rotacionados de acordo com a altura da pastagem. O manejo nutricional dos animais era realizado duas vezes ao dia, em cochos, com fornecimento na matéria natural de cerca de $2 \mathrm{~kg}$ de concentrado/dia, com acesso ao pasto e suplementação com silagem de milho na proporção de cerca de $2 \%$ do peso vivo. 
O manejo sanitário era feito diariamente, com a limpeza das baias sempre que os animais defecavam, e o banho era realizado às segundas-feiras pela manhã. O centro conta com disponibilidade de assistência médico-veterinária constante. As sessões de equoterapia tinham duração de 30 a 40 minutos e ocorriam durante o período da manhã das 7:00 $\mathrm{h}$ às 11:00 $\mathrm{h}$ de terça a sexta-feira e das 13:00 $\mathrm{h}$ às 17:00 $\mathrm{h}$ de segunda a quinta-feira, com uso preferencialmente alternado dos animais.

Durante o experimento, foram avaliados parâmetros fisiológicos relacionados ao estado de saúde dos cavalos segundo Leal (2007) e Gontijo et al. (2014), tendo como variáveis analisadas: o estado geral do animal, considerando características pela presença ou ausência de feridas, sendo contabilizadas feridas maiores que $1 \times 2 \mathrm{~cm}^{2}$ ou $4 \mathrm{~cm}$ de comprimento (AWIN, 2015) e escore corporal (Welfare Quality ${ }^{\circledR}$, 2011), usando escala de 0 a 5 (sendo 0 extremamente magro e 5 extremamente gordo), as quais foram realizadas ao início e fim do período de avaliação. Além disso, nos parâmetros cardiorrespiratórios avaliou-se a frequência cardíaca com auxílio de estetoscópio e a frequência respiratória por contagem visual dos movimentos torácicos, sendo que ambas as frequências foram contabilizadas por 15 segundos e multiplicado por quatro. As frequências cardiorrespiratórias foram aferidas antes, durante e após as sessões. Não houve necessidade de usar qualquer método de contenção durante a medição dos parâmetros fisiológicos devido à docilidade dos animais avaliados.

Os cavalos também foram avaliados quanto ao temperamento que apresentavam, seguindo metodologia de Momozawa et al. (2003) e Leal (2007), que se vale de um questionário aplicado aos tratadores e/ou pessoas envolvidas diretamente com a rotina diária dos animais, buscando classificá-los em escores que variavam de 1 a 3, sendo 1 de menor intensidade e 3 maior intensidade de expressão comportamental. Os comportamentos utilizados para caracterizar o temperamento dos animais durante as avaliações foram: brincalhão: tendência do animal a interagir com os estímulos do ambiente; curioso: tendência do indivíduo de interessar-se por objetos ou pessoas que se aproximem dele; nervoso: tendência do indivíduo de ser facilmente excitado, acarretando em mudanças de postura e comportamento; assustado: tendência do indivíduo em reagir com medo, apresentando reação de aversão ao estímulo. Aos temperamentos brincalhão e curioso foram atribuídos valores positivos de escore e aos temperamentos nervoso e assustado atribuídos valores negativos. O balanço dos escores dos indicadores de temperamento (soma dos indicadores positivos e negativos) foi usado para caracterizar o temperamento de cada animal. Também se buscou informações sobre o histórico do animal e o tempo de trabalho semanal.

As avaliações comportamentais foram seguidas usando-se um etograma adaptado de McDonnell \& Haviland (1995), Mills \& Riezebos (2005), Leal (2007) e Gontijo et al. (2014). Os comportamentos normais foram agrupados em: 
A) Distraído: estação que o animal fica com os olhos fechados ou semifechados e lábios relaxados (Cooper et al., 2000).

B) Alerta em estação: momento que o equino está com as orelhas em pé e em direção a movimentos ou sons (Mills \& Riezebos, 2005).

C) Deitado: equino em decúbito esternal ou lateral (Cooper et al., 2005).

D) Focinho rente ao chão: animal com o focinho rente ao chão (Cooper et al., 2005).

E) Cavar: um membro anterior do equino entra em contato com o solo para retirar porções de materiais que ali estão presentes (McDonnel \& Haviland, 1995).

F) Relinchar: som emitido pelos equídeos.

G) Morder outros animais: tentativa de morder outros animais devido a algum estímulo.

Os comportamentos anormais/estereotipados avaliados foram:

A) Movimentos aleatórios pela baia: animal se movimenta repetitivamente, como em círculo, podendo ser para qualquer direção (Houpt \& McDonnell, 1993; Mills \& Nankervis, 2005).

B) Movimentos repetidos de cabeça: equino balança a cabeça para cima e para baixo ou para um lado e para o outro (Cooper et al., 2000).

C) Dança de lobo ou síndrome do urso (weaving): animal balança a cabeça e o pescoço e os membros anteriores e posteriores (Mills \& Riezebos, 2005).

D) Aerofagia: o equino engole ar; a aerofagia pode ser sem apoio, somente engolindo o ar, ou com apoio, em que o animal apoia os dentes e fixa os incisivos em um objeto contraindo o pescoço, emitindo ou não um som (McGreevy \& Nicol, 1998).

E) Morder madeira: o animal morde a madeira como portas e baias (Mills \& Nankervis, 2005).

F) Coprofagia: o equino ingere as suas fezes ou de outro animal (Soave \& Brand, 1991).

G) Lambedura de cocho: o animal lambe repetitivamente o cocho após ingerido o alimento.

H) Bater na porta da baia: bater com os membros anteriores na porta da baia (Cooper et al., 2005).

I) Subir no cocho: equino apoia os membros anteriores sobre o cocho.

A metodologia utilizada para as observações foi do animal focal (Martin \& Bateson, 1993), onde o animal que seria utilizado na sessão equoterápica era observado por $30 \mathrm{~min}$ antes da sessão, 30 min durante a sessão e 30 min após a sessão, totalizando 90 min, nos dois turnos do dia (manhã e tarde), uma vez ao mês, durante cinco meses de experimento, totalizando 900 min por animal e 6.300 min de esforço amostral. Os comportamentos foram anotados em planilhas e também registrados por fotografia e gravações digitais e serão representados nas figuras e tabelas em minutos.

Para as observações comportamentais, foi realizado antes do início do período experimental um período de teste, para que a equipe pudesse avaliar os melhores locais para posicionamento do 
observador a fim de evitar ou minimizar qualquer estresse aos animais causados pela sua presença.

O delineamento utilizado foi inteiramente casualizado, sendo que os parâmetros cardiorrespiratórios foram analisados por análise de variância seguida pelo teste de Student-NewmanKeuls e as variáveis comportamentais e de temperamento foram analisadas por estatística não-paramétrica usando o teste de Kruskal-Wallis para sessão, tempo de serviço, escore corporal e animal e Wilcoxon para turno de observação e presença/ausência de feridas. Para todas as análises, considerou-se nível de significância de $p<0,05$.

\section{RESULTADOS E DISCUSSÃO}

Ao se analisar individualmente cada animal, não houve diferença $(p>0,05)$ quanto ao temperamento, tempo semanal de serviço, escore corporal, presença/ausência de feridas e idade (Tabela 1).

Tabela 1. Balanço de escore de temperamento, tempo semanal de trabalho (h), escore corporal (escala de 0 a 5), ausência (0) / presença (1) de feridas e idade em anos, dos equinos do Centro de Equoterapia do Campus Ceres IF Goiano.

\begin{tabular}{|c|c|c|c|c|c|c|c|c|c|}
\hline \multirow{2}{*}{ Animal } & \multicolumn{5}{|c|}{ Temperamento } & \multirow{2}{*}{$\begin{array}{c}\text { Tempo de } \\
\text { trabalho } \\
\text { semanal }(h)^{*}\end{array}$} & \multirow{2}{*}{$\begin{array}{c}\text { Escore } \\
\text { corporal* }\end{array}$} & \multirow{2}{*}{ Feridas** } & \multirow{2}{*}{$\begin{array}{c}\text { Idade } \\
\text { (anos)* }\end{array}$} \\
\hline & Brincalhão & Curioso & Nervoso & Assustado & Balanço & & & & \\
\hline A & 1 & 1 & 1 & 2 & -1 & 4 & 4 & 0 & 18 \\
\hline B & 2 & 2 & 3 & 2 & -1 & 10 & 4 & 0 & 12 \\
\hline C & 1 & 1 & 1 & 1 & 0 & 6 & 4 & 0 & 12 \\
\hline D & 2 & 1 & 3 & 2 & -2 & 4 & 4 & 0 & 12 \\
\hline $\mathrm{E}$ & 3 & 2 & 2 & 3 & 0 & 2 & 4 & 0 & 6 \\
\hline $\mathrm{F}$ & 1 & 1 & 2 & 1 & -1 & 10 & 3 & 0 & 17 \\
\hline G & 3 & 3 & 1 & 1 & +4 & 6 & 4 & 0 & 7 \\
\hline
\end{tabular}

$*$ Teste de Kruskal-Wallis $p>0,05$ e $^{* *}$ Teste de Wilcoxon $p>0,05$.

O relato dos entrevistados quanto ao temperamento dos animais utilizados no Centro demonstrou que a maioria foi enquadrado com balanço negativo. Para que um cavalo seja selecionado para as atividades equoterápicas ele deve possuir algumas características positivas, como docilidade, obediência, relação de confiança com praticante, resistência, rusticidade, facilidade de adaptação ao ambiente, grande peso corporal, boa aceitação ao contato/toque, e que tenha comportamento de disponibilidade de ajudar (Arantes et al., 2006). Desta forma, os animais A, B, D e F, que tiveram balanço negativo nas avaliações, aparentemente não deveriam ser utilizados no centro. Mas segundo a equipe entrevistada, todos os animais que são usados no centro respondem bem aos comandos usados na Equoterapia, o que justifica a permanência nas sessões.

Este caso pode ser exemplificado pelo animal D, que apresentou o pior balanço, mas segundo a 
equipe, esta tendência de temperamento negativo é expresso apenas no convívio com os demais animais, o que não ocorre durante as sessões já que este responde muito bem aos comandos dados pelo guia/terapeuta. Os animais C e E tiveram balanço neutro na avaliação da equipe do centro. $\mathrm{O}$ animal $\mathrm{G}$ foi relatado como dócil e de boa relação com as crianças, o que foi evidenciado no balanço altamente positivo de temperamento.

Na Figura 1, observa-se que de acordo com a categoria de intensidade de temperamento, a maioria demonstrou temperamento de baixa a média intensidade, corroborando Severo (2010), que caracteriza o cavalo utilizado nas práticas equoterápicas como dócil, submisso, obediente, tolerante e de bom temperamento. Mesmo os animais que são caracterizados pela equipe com temperamento mais intenso, ao serem colocados com os praticantes, atendem aos requisitos de um bom cavalo para Equoterapia, motivo pelo qual continuam sendo utilizados no centro.

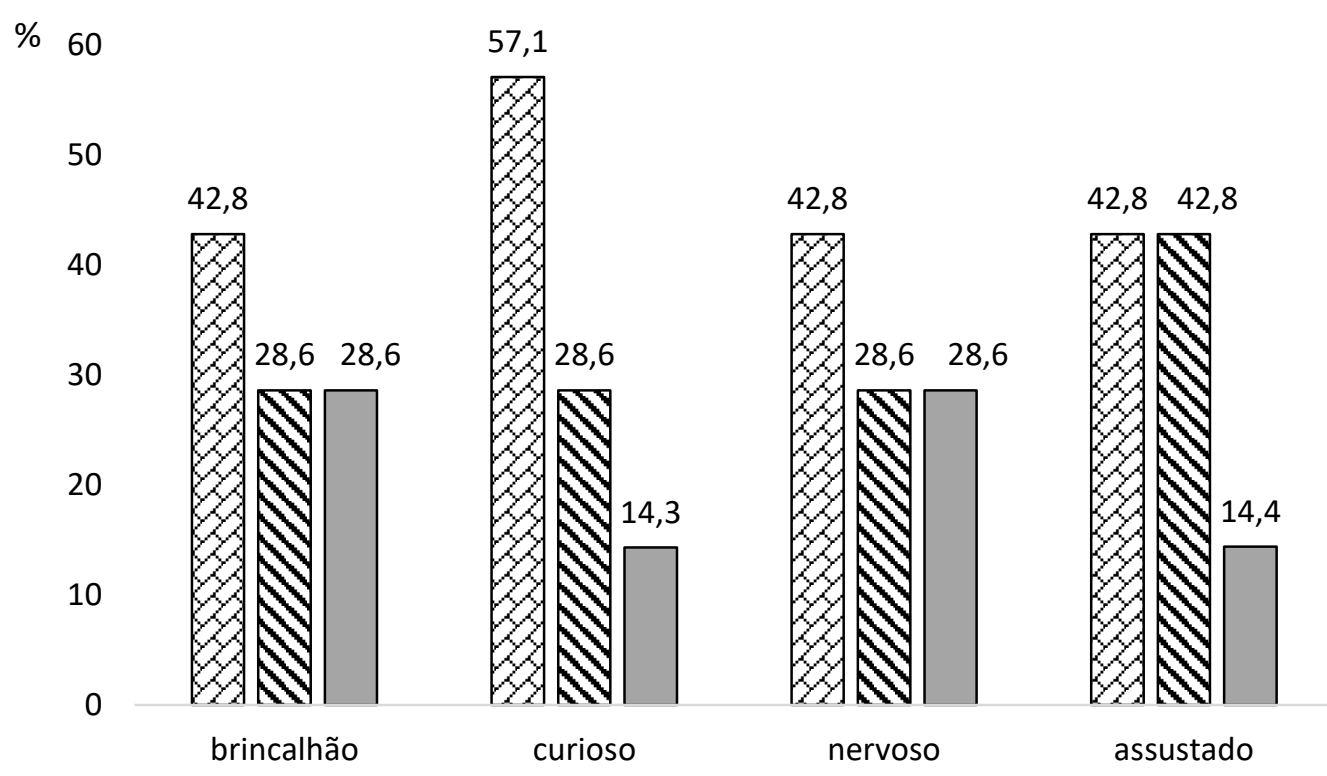

$\square 1 \square 2 \square 3$

Figura 1. Porcentagem dos equinos do Centro de Equoterapia do Campus Ceres IF Goiano para cada comportamento utilizado para avaliar o temperamento de acordo com a intensidade de expressão comportamental (1 menor intensidade e 3 maior intensidade).

Não houve diferença significativa para os valores de frequência respiratória $(p>0,05)$ quanto ao turno da sessão (manhã/tarde), discordando de Paludo et al. (2002), que encontraram maiores valores de frequência respiratória no período vespertino em cavalos do exército em exercício (20 minutos de galope em guia). No entanto, houve efeito significativo das frequências cardiorrespiratórias de acordo com o período avaliado em relação à sessão (início, meio e fim da sessão; $p<0,05$; Tabela 2). 
Tabela 2. Análise de variância da frequência cardíaca $(F C)$ e da frequência respiratória ( $F R$ ) dos cavalos do Centro de Equoterapia do Campus Ceres IF Goiano medidas no início, meio e final das sessões.

\begin{tabular}{cccc}
\hline FC & F & Valores Médios (bpm) & DP \\
\hline Início da sessão & 0,321 & $26,93^{* *}$ & 6,14 \\
Meio da sessão & 2,246 & 24,62 & 5,39 \\
Fim da sessão & 1,638 & 24,37 & 4,71 \\
\hline FR & $\mathbf{F}$ & Valores Médios (mpm) & DP \\
\hline Início da sessão & 4,279 & $26,75^{*}$ & 6,94 \\
Meio da sessão & 8,911 & $24,94^{* *}$ & 5,50 \\
Fim da sessão & 9,896 & $23,5^{* *}$ & 4,75 \\
\hline
\end{tabular}

Teste de Student-Newman-Keuls ${ }^{*} \mathrm{p}<0,05 \mathrm{e}^{* *} \mathrm{p}<0,01 . \mathrm{bpm}=$ batimentos por minuto; $\mathrm{mpm}=$ movimentos por minuto; DP = desvio padrão.

Os valores médios aferidos de FC e FR são corroborados por Cunningham (1999), estando dentro dos encontrados para um cavalo adulto normal (frequência cardíaca média de 32 a 44 bpm e frequência respiratória média de 8 a $16 \mathrm{mpm}$, podendo chegar até $40 \mathrm{mpm}$ segundo Colahan et al. (1999).

Percebeu-se que houve um aumento da frequência cardíaca na chegada dos animais à sessão e da frequência respiratória da chegada até os primeiros 15 minutos. Segundo Guyton \& Hall (2006), a aferição destes parâmetros por si só não é suficiente para se afirmar que os animais estivessem passando por uma situação de estresse crônico, mas servem como reflexo dos efeitos da ativação do sistema nervoso autônomo. Os valores de FC e FR comprovam que os animais não são utilizados nas sessões até o ponto de alterações fisiológicas relevantes, corroborando Lesimple et al. (2016). Tal ocorrência pode ser justificada pelo fato de que nas sessões de Equoterapia os animais ficam seguindo um percurso determinado e conhecido, aliado ao cuidado de minimizar o efeito do peso do praticante no animal. Adicionalmente, o exercício, e especialmente o livre exercício em torno de outros cavalos, é muito importante para o desenvolvimento e bem-estar do estado mental dos equinos.

Os animais demonstraram comportamentos caracterizados como normais, representados por estação distraído (63\% do tempo observado) e estação alerta (36\% do tempo observado). Os demais comportamentos: deitados, focinho rente ao chão, relinchar e morder outros animais não foram observados durante o período experimental (Tabela 3). A análise de variância aplicada às sessões de Equoterapia evidenciaram que existiu variação no comportamento dos animais antes, durante e após as sessões $(p<0,05)$ (Tabela 3). Comportamentos anormais foram observados com pouca frequência $(p>$ $0,05)$ ocorrendo em $14 \%$ dos animais avaliados. Na Tabela 3, observa-se que tais comportamentos foram agrupados em função da baixa expressividade, não havendo diferença significativa nas avaliações, exceto a aerofagia sem apoio e batendo na porta da baia $(p<0,05)$, que foram observados apenas no animal $D$, ocupando em média apenas $0,01 \%$ do tempo batendo na porta da baia e 0,003\% realizando aerofagia sem apoio. 
Tabela 3. Ocorrência de comportamentos normais e anormais (estereotipados), em minutos, dos cavalos do Centro de Equoterapia do Campus Ceres IF Goiano de acordo com o turno do dia e período nas sessões.

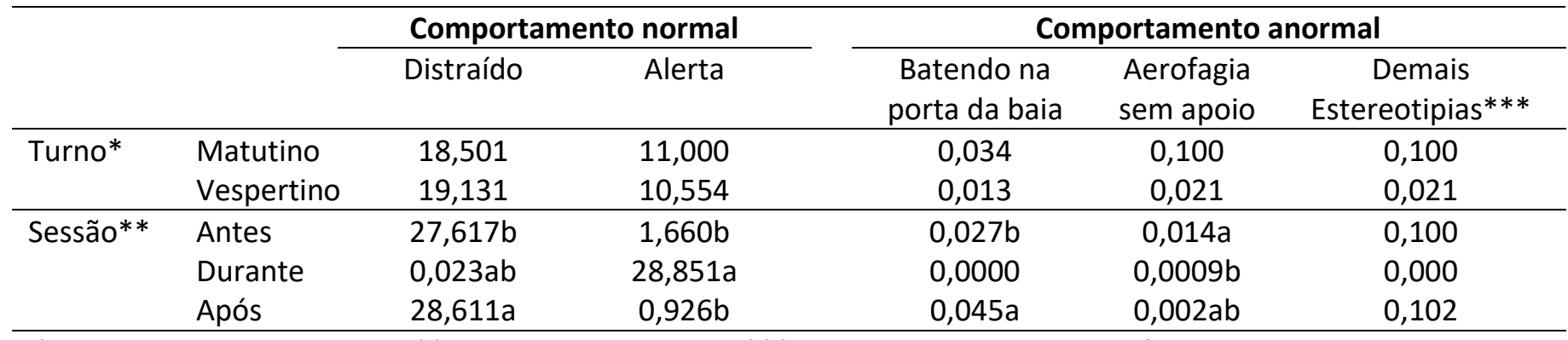

*Teste de Wicoxon $p>0,05 e^{* *}$ Kruskal-Wallis $p<0,05 * *$ Demais estereotipias: aerofagia com apoio, lambedura do cocho, mordendo o cabresto.

O comportamento na estação distraído ocorria nos momentos em que os cavalos não estavam sendo utilizados na sessão, em contraposição ao comportamento de alerta, que ocorria com maior frequência durante as sessões, o que é previsto, já que os animais devem ficar alerta aos comandos dados pelos equitadores e à resposta do praticante às ações equoterápicas.

Nos momentos em que não estavam sendo utilizados, os animais demonstraram maior relaxamento, devido à quase ausência de interação com o meio, ficando o animal praticamente imóvel, normalmente com as orelhas de lado e com os olhos fechados ou semifechados. Na natureza, os equinos passam cerca de $20 \%$ do seu tempo na estação distraído, já os equinos estabulados com restrição de alimento e sem contato físico e visual entre si, ficam cerca $65 \%$ do seu tempo nesta estação (McGreevy, 2004).

O comportamento de bater na porta da baia ocorria quando o animal escutava a movimentação dos tratadores antecedendo a alimentação e este demonstrava agitação e desejo de ser alimentado. Esse comportamento demonstra ansiedade e insatisfação por estar longe do seu alimento (McGreevy, 2004), tendo corrido em uma das observações 84 batidas. Após o término do trabalho, a equipe do Centro realizou uma dessensibilização com este animal a fim de diminuir a frequência de ocorrência do comportamento.

Waran (2001), Waters et al. (2002) e Popescu et al. (2019) relatam que a crescente ordem de comportamentos anormais ao longo do tempo, quando presente, deve-se à possível falta do hábito de pastejar e à falta de convivência social com outros do mesmo grupo. Os animais do Centro são alojados em baias individuais com contato visual frontal e possibilidade de cheirar e ouvir um ao outro, além do fato de serem soltos diariamente em piquetes com pastagem e contato com coespecíficos e possibilidade de expressar comportamentos naturais, diminuindo os comportamentos estereotipados aqui pouco observados.

A análise individual dos comportamentos mais frequentemente expressados - estação distraído 
e estação alerta - mostra que houve diferença significativa entre os animais $(p<0,05)$ (Figura 2$)$.
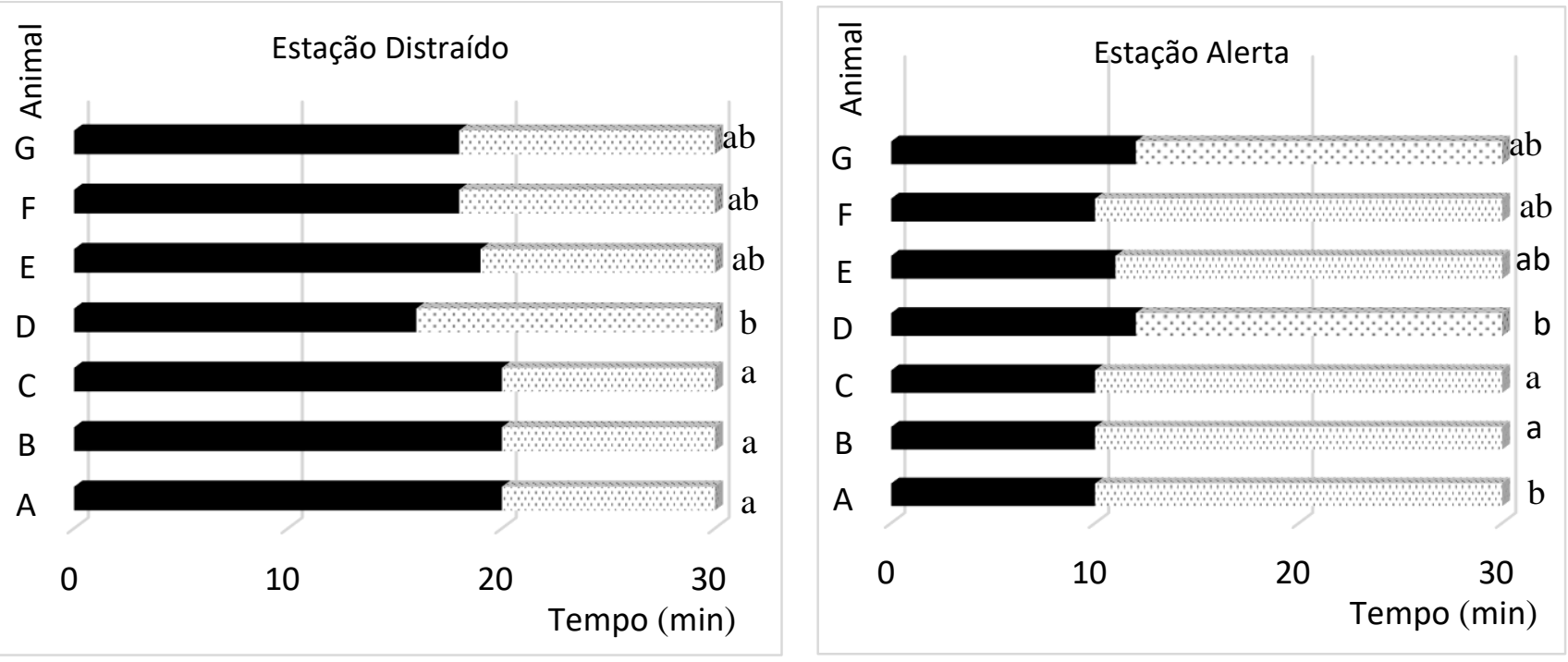

Figura 2. Tempo de expressão médio (minutos) do comportamento "Distraído" (A) e "Alerta" (B) dos cavalos do Centro de Equoterapia do Campus Ceres IF Goiano.

O animal $D$ foi o que permaneceu menos tempo na estação distraído (Figura 2), em contraposição à estação alerta que o mesmo animal dispendeu a maior parte de seu tempo (Figura 3). Este animal também foi o único a apresentar estereotipias de aerofagia sem apoio e bater na porta da baia, mesmo que em pequena parte do tempo observado. Quando se observa a Tabela 1, percebe-se que o animal demonstra maior intensidade de temperamento assustado e nervoso, de acordo com os relatos da equipe, principalmente quando está em contato com os demais cavalos do Centro; o que não ocorre quando este é utilizado nas sessões, onde expressa uma excelente resposta aos comandos dados pelos equitadores e pelo praticante, motivo pelo qual a equipe mantém o animal ativo, mas procurando não o exacerbar com uma carga de trabalho alta.

A estação de alerta na sua maior parte ocorre quando existe algum estímulo relevante ao animal, como sons ou o momento de alimentação, e uma das principais características da estação alerta é a posição da orelha, que fica ereta e em direção ao estímulo e os olhos bem dilatados (Mills \& Riezebos, 2005). Conforme Smythe (1990) apud Ferrari (2011), além da expressão corporal, os cavalos possuem padrões comunicativos por envio de sons característicos e expressivos, com sentidos muito sensíveis, favorecendo o contato com o homem. O olfato é bem desenvolvido e permitindo a identificação dos alimentos. Uma das expressões que demonstram seus sentimentos é quando expandem e contraem as narinas podendo significar suspeita, medo ou interesse. A posição das orelhas quando estão para trás indicam que o animal está atento ou irritado.

No momento em que o animal está em alerta existe um maior aprendizado. Segundo Severo (2010), o cavalo tem boa memória, inteligência razoável e responde bem ao adestramento repetitivo. Suas experiências são construídas desde a tenra idade, e hábitos inadequados são difíceis de eliminar. 


\section{CONCLUSÃO}

A ocorrência de comportamentos normais, os indicadores de saúde dentro da normalidade e o bom indicador de nutrição mostram que os cavalos do Centro de Equoterapia apresentavam bem-estar adequado.

\section{AGRADECIMENTOS}

Ao setor de Equoterapia do Instituto Federal Goiano - Campus Ceres.

\section{REFERÊNCIAS BIBLIOGRÁFICAS}

Arantes, L.G.; Viadanna, P.H.; Souza, R.R. \& Souza, M.M.O. 2006 A Participação do Médico Veterinário na Escolha e Treinamento de Cavalos para a Prática de Equoterapia. Veterinária Notícias, 12(2): 18.

AWIN. 2015. Animal Welfare Indicators. AWIN Welfare Assessment Protocol for Horses. Disponível em: https://air.unimi.it/retrieve/handle/2434/269097/384836/AWINProtocolHorses.pdf.

Botreau, R.; Bracke, M.B.M.; Perny, P.; Butterworth, A.; Capdeville, J.; Van Reenen, C.G. \& Veissier, I. 2007. Aggregation of measures to produce an overall assessment of animal welfare. Part 2: analysis of constraints. Animal 1(8):1188-1197.

Colahan, P.T.; Mayhew, I.G. \& Merrit, A.M. 1999. Respiratory system. P.544- 547. In: Colahan, P.T.; Mayhew, I.G. \& Merrit, A.M. (ed.). Equine Medicine and Surgery. 5 ed. Missouri, Mosby. 90p.

Cooper, J.J.; McDonald, L. \& Mills, D.S. 2000. The effect of increasing visual horizons on stereotypic weaving: implications for the social housing of stabled horses. Applied Animal Behaviour Science 69(1): 67-83.

Cooper, J.J.; Mcall, N. \& Johnson, S. 2005. The short-term effects of increasing meal frequency on stereotypic behaviour of stabled horses. Applied Animal Behaviour Science 90(3-4): 351-364.

Cunningham, J.G. 1999. Tratado de Fisiologia Veterinária. 2 ed. Rio de Janeiro, Guanabara Koogan.

Crizanto, E.C.G.S. 2002. Avaliação Comportamental e Fisiológica em Cavalos de Patrulha e Hipismo. Dissertação (Mestrado em Psicobiologia). Universidade Federal do Rio Grande do Norte, Natal, RN. 56p. 
ANDE. 1999. Associação Nacional de Equoterapia. Equoterapia: 0 que é? Disponível em: <http://www.equoterapia.com.br/o_que_e-definicao.php>. Acesso em: 14 nov. 2018.

Farm Animal Welfare Council. 1992. FAWC updates the five freedoms. The Veterinary Record 131: 357.

Ferrari, J.P. 2011. A prática do Psicólogo na Equoterapia. Monografia (Trabalho de Graduação Interdisciplinar). Faculdade de Psicologia, Universidade Presbiteriana Mackenzie, São Paulo, SP. 76p.

Gontijo, L.A.; Cassou, F.; Junior, P.V.M.; Alves, G.E.S.; Bringel, B.; Ribeiro, R.M.; Lago, L.A.; Faleiros, R.R.; 2014. Bem-estar em equinos de policiamento em Curitiba/PR: indicadores clínicos, etológicos e ritmo circadiano do cortisol. Ciência Rural 44: 7.

Guyton, A.C. \& Hall, J.E. 2006. Tratado de Fisiologia Médica. 11 ed. Rio de Janeiro, Elsevier. 1115p.

Houpt, K.A. \& McDonnell, S.M. 1993. Equine Stereotypies. Compendium on Continuing Education for the Practicing Veterinarian 15(9): 1265-1271.

Konieczniak, P.; Dias, I.F.T.; Caleffo, T.; Sinhorini, W.A. \& Guirro, E.C.B.P. 2014. Estereotipias em equinos. Veterinária em Foco 11(2). 127 - 136.

Leal, B.B. 2007. Avaliação do Bem-estar dos Equinos de Cavalaria da Polícia Militar de Minas Gerais: Indicadores Etológicos, Endocrinológicos e Incidência de Cólica. Dissertação (Mestrado em Ciência Animal). Universidade Federal de Minas Gerais, Belo Horizonte - MG. 89p.

Lesimple, C.; Poissonnet, A. \& Hausberger M. 2016. How to keep your horse safe? An epidemiological study about management practices. Applied Animal Behaviour Science 181: 105-114.

Malinowski, K. 2004. The Horse Industry's Responsibility to Animal Welfare. Disponível em: <www.rce.rutgers.edu>. Acessado em: 30 nov. 2018.

Martin, P. \& Bateson, P. 1993. Measuring Behavior: An Introductory Guide. 2 ed. Cambridge, University Press. 222p.

McDonnel, S.M. \& Haviland, J.C.S. 1995. Agnostic ethogram of the equid bachelor band. Applied Animal Behaviour Science 43(3): 147-188.

McGreevy, P. \& Nicol, C.J. 1998. Physiological and behavioral consequences associated with short term prevention of crib-biting in horses. Physiology and Behaviour 65(1): 15-23. 
McGreevy, P. 2004. Equine Behavior: A Guide for Veterinarians and Equine Scientists. Londres, Saunders. $357 p$.

Mills, D. S. \& Riezebos, M. 2005. The role of the image of a conspecific in the regulation of stereotypic head movements in the horse. Applied Animal Behaviour Science 91(1-2): 155-165.

Mills, D.S. \& Nankervis, K. 2005. Comportamento Equino. São Paulo, Roca. 213p.

Ministério da Agricultura, Pecuária e Abastecimento (MAPA). 2015. Animal, Equídeos. São Paulo. Acessória de Comunicação e Eventos. 56p.

Momozawa, Y.; Ono, T.; Sato, F.; Kikusui, T.; Takeuchi, Y.; Mori, Y. \& Kusunose, R. 2003. Assessment of equine temperament by a questionnaire survey to caretakers and evaluation of its reliability by simultaneous behavior test. Applied Animal Behaviour Science 84(2): 127-138.

Outram, A. K.; Stear, N.; Bendrey, R.; Olsen, S.; Kasparov, A.; Zaibert, V.; Thorpe, N \& Evershed, R. 2009. The Earliest Horse Harnessing and Milking. Science 323: 1332-1335.

Pagliosa, G.M. ; ALves, G.E.S. ; Faleiros, R.R. ; Leal, B.B. ; Ening, M.P. 2008. Estudo Epidemiológico de Estereotipias em Equinos de Cavalaria Militar. Archives of Veterinary Science 13 (2):104-109.

Paludo, G.R.; McManus, C.; Melo, R.Q.; Cardoso, A.G.; Mello, F.P.S.; Moreira, M. \& Fuck, B. H. 2002. Efeito do Estresse Térmico e do Exercício sobre Parâmetros Fisiológicos de Cavalos do Exército Brasileiro. Revista Brasileira de Zootecnia 31(3): 1130-1142.

Popescu, S.; Lazar, E.A.; Borda, C.; Niculae, M.; Sandru, C. D. \& Spinu, M. 2019. Welfare Quality of Breeding Horses Under Different Housing Conditions. Animals 9(81). 13p.

Rezende, M.J.M.; Mcmanus, C.; Martins, R.D.; Oliveira, L.P.G.; Garcia, J.A.S. \& Louvandini, H. 2006. Comportamento de cavalos estabulados do exército brasileiro em Brasília. Ciência Animal Brasileira 7(3): 327-337.

Severo, J.T. 2010. Equoterapia: Equitação, Saúde e Educação. São Paulo: Senac. 363p.

Soave, O. \& Brand, C.D. 1991. Coprophagy in animals: a review. Cornell Veterinary 81 (4): 357-365.

Vieira, A.R.A. 2006. Prevalência e Desgaste Anormal dos Dentes Incisivos e Incidência de Cólica em Equinos Estabulados Apresentando Distúrbios do Comportamento: Análise de um Total de 407 Equinos. Dissertação (Mestrado em Ciência Animal). Universidade Federal de Viçosa, Viçosa - MG. 47p. 
Waran, N.K. 2001. The Social Behaviour of Horses. P.247-274. In: Keeling, L. J.; Gonyou, H. W (ed.). Social Behaviour in Farm Animals. CABI, Wallingford, UK, 406p.

Waters, A.J.; Nicol, C.L. \& French, N.P. 2002. Factors influencing the development of stereotypic and redirected behaviours in young horses: Findings of a four-year prospective epidemiological study. Equine Veterinary Journal 34: 572.

Welfare Quality. 2011. Welfare Monitoring System. Assessmente Protocol for Horses. version 2.0. Report number 569. 43p. 